\title{
Colour Contrast Sensitivity Changes caused by Peripheral Retinal Laser Photocoagulation
}

\author{
CHRIS R. CANNING, NICK STRONG, THOMAS A. BERNINGER, \\ GEOFFREY B. ARDEN
}

London, Southampton, Leicester and Munich

\begin{abstract}
Summary
Macular phototoxicity is known to occur with laser use, and there is evidence that the wavelength of the light used influences this effect. In this study, a computer based colour contrast sensitivity test was used to assess the immediate macular effects of photocoagulation of peripheral flat retinal holes in otherwise normal retinas, using blue-green $(488$ and $514 \mathrm{~nm})$, yellow $(577 \mathrm{~nm})$, orange $(595 \mathrm{~nm})$ or red $(647 \mathrm{~nm})$ laser light. The laser aiming beam was not allowed to traverse the macula at any stage during treatment. No protan or deutan axis threshold changes were noted in the 17 patients tested irrespective of the laser wavelength used. Tritan axis sensitivity was significantly reduced one hour after treatment with the blue-green laser, but no tritan axis change was found after treatment with longer wavelength lasers. The effect was no longer present the day after treatment in the subjects tested. The results show that even peripheral retinal treatment with blue-green laser can cause acute macular phototoxicity.
\end{abstract}

Short wavelength laser treatment of the macula itself results in damage, probably from absorption of the light by luteal pigment. ${ }^{1,2}$ In addition, extensive extra-macular panretinal photocoagulation in diabetics using argon blue-green produces a tritan defect, which may be permanent. ${ }^{3,4}$ Diabetics often do not have normal colour vision before their laser treatment, so the effect of the laser is difficult to detect.

The aim of the present study was to compare acute colour contrast sensitivity (CCS) changes induced by limited extra-macular photocoagulation in patients with normal colour vision, using lasers of various wavelengths.

\section{Methods}

It is policy at Moorfields Eye Hospital to offer prophylactic laser photocoagulation to patients who present with symptoms of acute posterior vitreous separation together with retinal horse-shoe tears overlying less than one disc diameter of subretinal fluid.

Patients with single tears were recruited into this study after giving informed consent. All patients with other preexisting eye disease or surgery were excluded. The patients were randomly assigned to argon blue-green, dye yellow, dye orange or krypton red laser treatment.

A Goldman 3-mirror lens was used to visualise the treatment site. The laser spot size

From: Moorfields Eye Hospital, London, England (Drs Canning, Strong, Berninger, Arden), Southampton Eye Hospital (Mr Canning), Leicester Royal Infirmary, Leicester, England (Dr Strong), Universitats-Augenklinik, Munich, West Germany (Dr Berninger).

Correspondence to: Mr C. Canning FRCS, FCOphth, Southampton Eye Hospital, Wilton Av., Southampton SO9 4XW, United Kingdom. 
Table I Details of patients treated

\begin{tabular}{lclc}
\hline Laser & Age/Sex/Eye & $\begin{array}{l}\text { Visual } \\
\text { Acuity }\end{array}$ & $\begin{array}{c}\text { No of } \\
\text { Burns }\end{array}$ \\
\hline Blue/green & 58/M/R & $6 / 24$ & 300 \\
& 65/F/R & $6 / 18$ & 37 \\
& 59/M/R & $6 / 9$ & 111 \\
& & $6 / 9$ & 128 \\
Yellow/ & 22/M/R & $6 / 5$ & 105 \\
orange & 59/F/R & $6 / 9$ & 75 \\
& 39/F/L & $6 / 7.5$ & 110 \\
& 33/F/L & $6 / 9$ & 78 \\
& 45/F/R & $6 / 5$ & 122 \\
Red & 50/M/L & $6 / 6$ & 126 \\
& 68/F/R & $6 / 6$ & 120 \\
& 43/F/R & $6 / 6$ & 104 \\
& 27/F/R & $6 / 9$ & 91 \\
& 58/F/R & $6 / 9$ & 79 \\
& 60/M/R & $6 / 5$ & 74 \\
& 55/F/L & $6 / 6$ & 134 \\
& 56/M/R & $6 / 6$ & 126 \\
\hline
\end{tabular}

was set at 200 microns, the duration at 0.1 seconds, and the energy setting was adjusted to create a grey-white retinal burn. A double row of confluent burns was applied to surround the tear. Care was taken to avoid pointing the aiming beam at the macula any time during the treatment.

The colour contrast sensitivity was measured immediately before and again one hour after treatment, using the method described by Arden et al. ${ }^{5,6}$ Six patients were tested again the day after treatment.

The method of measuring colour contrast sensitivity is to establish first each test subject's isoluminance value on the protan, deutan and tritan confusion lines using a heterochromatic flicker fusion technique., Each colour confusion axis is then tested separately. Two colours that are truly isoluminant and lie on either side of the confusion axis are presented as two cycles of a 0.8 cycle/degree square wave grating in the central $25 \%$ of a monitor screen whose background colour is a mixture of the two. The grating thus subtends a square of $2.5 \times 2.5$ degrees at the eye. The test starts with low contrast colours, so the subject sees a blank screen filled with the background colour. The contrast between the colour of the bars increases gradually until the subject indicates that he is able to see them.

The change in CCS from before to after treatment in each group was analysed statistically using a paired t-test method.

\section{Results}

The table lists basic patient data. Six eyes were treated with blue-green, six with yellow or orange, and five with red laser. There are no significant differences between the groups as regards the patients' age or the number of laser burns applied. The figure plots CCS before and after treatment in these 17 eyes on the protan, deutan and tritan axes. No significant changes were observed on the protan or deutan axes. Sensitivity on the tritan axis, however, was significantly worse after treatment with blue-green laser $(\mathrm{p}<0.01)$, but not for other wavelengths.

In the six patients (two in the blue-green group) who were retested the day after treatment, the tritan axis sensitivity did not differ significantly from the baseline value.

\section{Discussion}

The computer based CCS test system used here has a number of advantages over other colour tests which makes it suitable for detecting quite subtle changes in colour vision. The Farnsworth Munsell 100 hue test ${ }^{7}$ has a number of inherent shortcomings. The tints used are not truly insoluminant for the test subject, tints may vary with age and use, and the subject's perception of the tints may be affected by such factors as cataract and tinted glasses. Thus the subject may arrange the tints not only by hue but also by luminance. The computer system, on the other hand, establishes each subject's isoluminance values at the beginning of each test. The increments in hue separation which are available are fine by comparison with the 85 test discs in the 100 hue. Indeed, it is this very precision which makes it unsuitable for the study of diabetics, who manifest coarse colour vision defects. ${ }^{4,8}$

The results show that even peripheral laser treatment, with no direct posterior pole exposure either to the aiming or treatment beams, is able acutely to affect macular function. The effect occurs only with short wavelength light, and not with yellow or longer wavelengths. It is not due to acute photopigment bleachingregeneration of cone pigments occurs with a time constant of 90 seconds, so that full regeneration would be present at one hour. In addition, previous work using the computer based colour contrast test system has shown that 

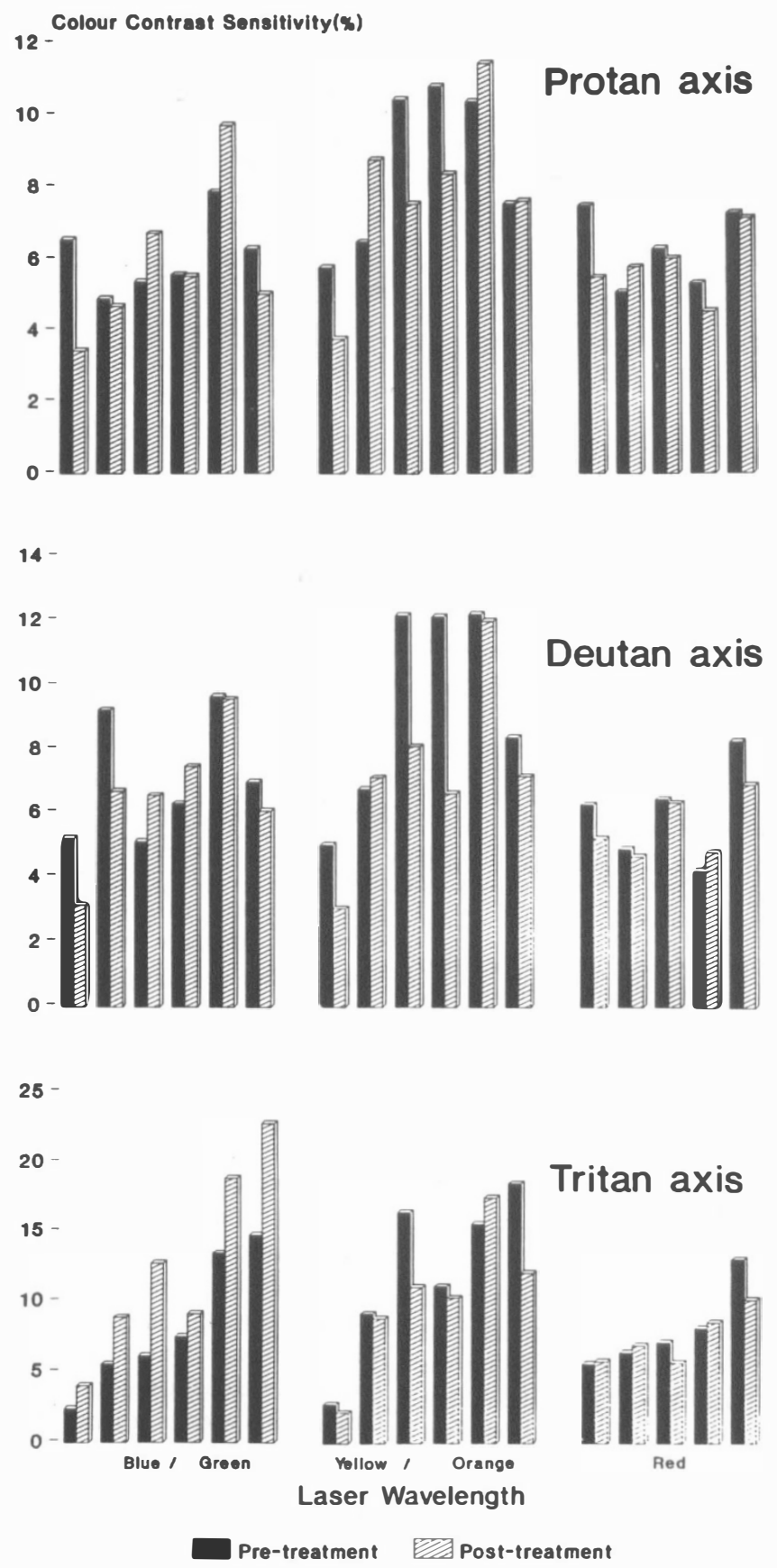

Fig. 1. Summary of the CCS results from the 17 patients. Each pair of vertical bars represents one patient, the first being the pre-treatment value (solid) and the second the one hour post-treatment value (hatched). There are 6 patients in the blue-green group, 7 in the yellow and orange group, and 6 in the red group. The results are divided into protan axis (top), deutan (middle) and tritan (bottom). Note that while the CCS post-treatment may be higher (representing a worsening of the CCS) or lower (an improvement) in most subsets, all patients treated with bluet green laser showed a worsening on the tritan axis (bottom left). 
intense incoherent white light does not produce a measurable drop in CCS an hour after exposure. ${ }^{9}$

Short wavelength light scatters more inside the eye than longer wavelengths. The macula thus has a greater exposure to scattered light when blue-green laser is used in the retinal periphery as compared to longer wavelengths. This effect is likely to be less important than the peculiar sensitivity of cones to blue light, however. Loss of tritan sensitivity has also been found in laser users after a treatment session with the blue-green laser, and it has been demonstrated that reflection of the aiming beam off the surface of the contact lens used may be responsible for this. ${ }^{9}$ No change in CCS thresholds were noted in the same operators after they used longer wavelength lasers.

The reduced tritan sensitivity lasted at least one hour, but had resolved within a day. The much higher and repeated doses of laser involved in panretinal photocoagulation of diabetics may produce more permanent damage, which may in part explain the tritan defect seen in such patients. ${ }^{3,4}$ In addition, a recent study of laser operators found a significant correlation between the number of years of laser use and the tritan threshold. ${ }^{10}$ In all users with more than six years experience the tritan threshold was elevated. Thus the toxic effect may be cumulative.

This paper presents further evidence that short wavelength laser light is acutely toxic to the macula. Wherever possible short wavelength laser should be avoided even for peripheral retinal treatment.

References

${ }^{1}$ Geeraets WJ and Berry ER: Ocular spectral characteristics as related to hazards from lasers and other light sources. Am J Ophthalmol 1968; 66: 15-20.

${ }^{2}$ Mainster MA: Wavelength selection in macular photocoagulation: tissue optics, thermal effects and laser systems. Ophthalmology 1986; 93: 952-8.

${ }^{3}$ Birch $\mathbf{J}$ and Hamilton AM: Xenon arc and argon laser photocoagulation in the treatment of diabetic disc neovascularisation. Part 2 -effect on colour vision. Trans Ophthalmol Soc UK 1981; 101: 93-9.

${ }^{4}$ Birch J: Colour vision changes following different types and amounts of argon laser photocoagualtion in the treatment of diabetic retinopathy. Doc Ophthalmol Proc Ser 1987; 46: 31-6.

${ }^{5}$ Arden GB, Gunduz K, Perry S: Colour vision testing with a computer graphic system: preliminary results. Doc Ophthalmol 1988; 69: 111.

${ }^{6}$ Arden GB, Gunduz K, Perry S: Colour vision testing with a computer graphics system. Clin Vision Sci 1988; 2: 303.

${ }^{7}$ Farnsworth D: The Farnsworth-Munsell 100 hue test and dichotomous tests for colour vision. JOPt Soc Am 1943; 10: 568-78.

${ }^{8}$ Gunduz K and Arden GB: Changes in colour contrast sensitivity associated with operating argon lasers. Br J Ophthalmol 1989; 73: 241-6.

${ }^{9}$ Peduzzi M, Longanesi L, Ascari A, et al: Screening of early color vision loss in diabetic patients. $J$ Fr Ophthalmol 1989; 12: 791-6.

${ }^{10}$ Berninger TA, Canning CR, Gunduz K, Strong N, Arden GB: Using argon laser blue light reduces ophthalmologists' color contrast sensitivity. Arch Ophthalmol 1989; 107: 1453-8. 